\title{
Priming Effect Induced by the Use of Different Fertilizers on Soil Functional Diversity
}

\author{
Bogdan-Mihai ONICA ${ }^{1}$, Roxana VIDICAN ${ }^{*}$, Valentina SANDOR ${ }^{2}$, Traian BRAD ${ }^{3}$, Mignon SANDOR ${ }^{2}$ \\ ${ }^{1}$ University of Agricultural Science and Veterinary Medicine, Department of Plant Culture, 3-5 Calea \\ Manastur Cluj-Napoca, Romania \\ ${ }^{2}$ University of Agricultural Science and Veterinary Medicine, Department of Environmental and Plant \\ Protection, 3-5 Calea Manastur Cluj-Napoca, Romania \\ 3"Emil Racovita" Institute of Speleology, Cluj-Napoca, Romania \\ *corresponding author, e-mail: roxana.vidican@usamvcluj.ro
}

Bulletin USAMV series Agriculture 74(2)/2017

Print ISSN 1843-5246; Electronic ISSN 1843-5386

DOI 10.15835/buasvmcn-agr: 0017

\begin{abstract}
Agricultural practices, such as the use of fertilizers, can change the structure and function of soil microbial community. Monitoring and assessing the soil microbiota and its dynamics related to different factors can be a powerful tool for understanding basic and applied ecological contexts. The main objective of this paper was to assess the changes of carbon turnover rate and the microbial metabolic activity, when different types of fertilizers were used, process called priming effect. A microcosm experiment was designed and performed under controlled temperature and humidity and the soil samples were analyzed using the MicroResp technique. Results show that the integration in soil of different carbon sources, such as green manure, can lead to a positive priming effect and integration of mineral fertilizers can lead to negative priming effect. The carbon sources with the highest respiratory activity were $\alpha$-ketoglutaric acid, malic acid, oxalic acid, citric acid, while the lowest respiratory activity was obtained in case of arginine.
\end{abstract}

Keywords: Community level physiological profile, Fertilizers, MicroResp, Soil, Functional diversity, Priming effect.

\section{INTRODUCTION}

Agricultural practices can have a great influence on the diversity, size, activity and composition of the microbial community in the soil. Unsuitable use of farmland and management strategies can harm the soil microbial community, and this is an important issue due to the fact that healthy microbial communities are essential to a sustainable agricultural ecosystem, because microorganisms mediate continuously the process of nutrient transformation (Ge et al., 2013). However, changes have been observed in soil microbial communities due to factors such as the use of fertilizers, cultivated plant species, the use of pesticides, tillage practices and the use of organic or conventional agricultural management strategies (Wakelin et al., 2008).
Banning et al. (2012) suggest that microbial communities in soil are adapted to decomposition of carbon sources specific to the original soil they come from. By processes that occur during ecological succession, complex carbon substrates structures are produced, therefore mature ecosystems can present a greater amount of carbon sources as well as greater diversity (Banning et al., 2012). The capacity of soil microbial communities to metabolize different carbon sources is known as community level physiological profile (Sradnick et al., 2013). Changes based on selection in soil microbiology occur in a context that encompasses the potential diversity supported by the soil type. However, soil is the main factor determining the functionality and composition of the microbial community, so the physicochemical and environ- 
mental factors will interact in complex ways influencing microbial diversity and its functionality (Wakelin et al., 2008).

Soil microbial community and activity monitoring can be a powerful tool for understanding applied ecological context (Frąc et al., 2012). To assess the health and activity, a basic parameter is to measure carbon dioxide, which is released by the soil microbial community during decomposition of carbon substrates. A method that can be used to assess the soil microbial community activity is MicroResp (Campbell et al., 2003).

Functional diversity of microbial communities in soil stems from genetic variability in a taxon, environmental effects on genetic expression, and ecological interactions between taxa. Functional diversity, rather than taxonomic, can provide a better understanding of microbial roles in ecosystems (Pignataro et al., 2012).

The response of terrestrial ecosystems to nutrient input is related to belowground processes, especially those produced by microorganisms, by increasing carbon input into soil, inducing the mechanism called "priming effect" (Lagomarsino et al., 2007).

Priming effect was discovered in 1926 by Löhnis when the author studied the decomposition of green manure of legume plants into the soil, and discovered that the mineralization of humus $\mathrm{N}$ is increased. In the next 20 years the phenomenon has not been studied until the middle of the 1940 s and in the 1950s by Broadbent and its collaborators (Kuzyakov et al., 2000).

The concept of priming effect represents the increase in soil organic matter mineralization, this acceleration being induced by the addition of a carbon or other nutrient sources (Bird et al., 2011).

Priming effect may be apparent when the extra $\mathrm{CO}_{2}$ results from the respiration of endogenous microorganisms or it may be real, a phenomenon connected by the mineralization of organic matter in the soil. When assessing the priming effect, it is important to distinguish the $\mathrm{CO}_{2}$ produced by the nutrient input. The apparent priming effect is controlled mainly by two mechanisms: the increase turnover of microbial biomass and the activation of microbial metabolism (Blagodatskaya et al., 2007).

Abiotic factors such as temperature, $\mathrm{pH}$ or soil moisture are the main factors that control carbon turnover and act especially by changing the microbial communities that mineralize organic matter from soil and plant residues (Blagodatskaya and Kuzyakov, 2008).

The concept of priming effect has been addressed in many ways, such as the addition of plant residues, dead microorganisms, mineral nitrogen and simple or complex organic substrates (Kuzyakov et al., 2000). Some studies indicate that incorporating organic fertilizer such as green manure and straw into the soil leads to increased mineralization of soil organic matter (Fontaine et al., 2007). Sustainable agriculture presents a major interest, because, compared with intensive agriculture, the soil quality is improved. Soil quality is directly linked with the microbial biodiversity and its metabolic capabilities. The type of fertilizer used in the field (mineral and organic fertilizer) on long term has an important impact on soil fertility and on microbial biodiversity. The aim of this work is to assess the influence of adding different types of fertilizers on carbon turnover and on the community level physiological profile immediately after application, process known as the priming effect. To compare the changes in the soil microbial communities between mineral and organic fertilization, three wide used organic fertilizers where chosen (i.e. green manure, slurry manure, cattle manure). In order to achieve the aim of this research, a microcosm experiment was designed and performed under controlled temperature and humidity.

\section{MATERIALS AND METHODS Experimental design}

In order to assess the soil microbial community changes due to different fertilizers use, a microcosm experiment was conducted. However, the experiment was designed to use two types of soil, chernozem and luvisoil, four types of fertilizers (mineral fertilizer, mustard as green manure, slurry manure and cattle manure), and two types of water regime (a normal water regime and a drought regime). In each microcosms, one individual of Lumbricus terrestris, one Aporectodea caliginosa and 200 individuals of Folsomia candida (Collembola) were added to simulate the activity of soil microbial community. The columns were closed with fine mesh to prevent escaping of fauna. Each treatment was repeated three times, resulting a total of 60 microcosms $(2$ soil types $\times$ 
Tab. 1. Carbon substrates used in MicroResp

\begin{tabular}{llll} 
Carbon substrates & & \\
\hline Carbohydrates & & Amino acids & \\
\hline D-trehalose & $\mathrm{C}_{12} \mathrm{H}_{22} \mathrm{O}_{11}$ & L-arginine & $\mathrm{C}_{6} \mathrm{H}_{14} \mathrm{~N}_{4} \mathrm{O}_{2}$ \\
\hline D-galactose & $\mathrm{C}_{6} \mathrm{H}_{12} \mathrm{O}_{6}$ & $\gamma$-aminobutyric acid & $\mathrm{C}_{4} \mathrm{H}_{9} \mathrm{NO}_{2}$ \\
\hline L-arabinose & $\mathrm{C}_{5} \mathrm{H}_{10} \mathrm{O}_{5}$ & L-lysine & $\mathrm{C}_{6} \mathrm{H}_{14} \mathrm{~N}_{2} \mathrm{O}_{2}$ \\
\hline D-glucose & $\mathrm{C}_{6} \mathrm{H}_{12} \mathrm{O}_{6}$ & L-alanine & $\mathrm{C}_{3} \mathrm{H}_{7} \mathrm{NO}_{2}$ \\
\hline D-fructose & $\mathrm{C}_{6} \mathrm{H}_{12} \mathrm{O}_{6}$ & L-cysteine & $\mathrm{C}_{3} \mathrm{H}_{7} \mathrm{NO}_{2} \mathrm{~S}$ \\
\hline Carboxylic acids & & Amino sugar & \\
\hline Oxalic Acid & & $\mathrm{N}$-acetylglucosamine & $\mathrm{C}_{8} \mathrm{H}_{15} \mathrm{NO}_{6}$ \\
\hline$\alpha$ - ketoglutaric acid & $\mathrm{C}_{2} \mathrm{H}_{2} \mathrm{O}_{4}$ & & \\
\hline Citric Acid & $\mathrm{C}_{5} \mathrm{H}_{6} \mathrm{O}_{5}$ & & \\
\hline L-malic acid & $\mathrm{C}_{6} \mathrm{H}_{8} \mathrm{O}_{7}$ & & \\
\hline
\end{tabular}

Source: (Campbell et al., 2003)

5 fertilizers (with control) $\times 2$ water regimes $\times 3$ repetitions).

Before the experiment start, the soil was sieved and stored at $-18{ }^{\circ} \mathrm{C}$ to eliminate the native fauna.

\section{Community level physiological profiling}

MicroResp is a colorimetric method based on the principle of respiration by the microbial community due to metabolism of carbon sources using a 96-well microplate system. MicroResp provides an immediate response to these substrates and reflects microbial activity by measuring responses in the first 4-6 hours (Campbell et al., 2010; Sassi et al., 2012). However, MicroResp consists of two microtiter plates placed face to face. One is the deep-well plate and the other is the detection plate (Campbell et al., 2003). In the deep-well plate, the soil samples and carbon sources are inserted, and the detection plate is a system which detects the evolved carbon dioxide using cresol as an indicator (Campbell et al., 2003). The two plates are sealed face to face using a silicone rubber such that each well from the deep-well plate communicates with one from the detection plate and is held together firmly with a metal clamp.

The 15 carbon sources used in MicroResp method were selected to be ecologically relevant to soil and to be able to dissolve in water (Tab. 1) (Chapman et al., 2007). The sample reading is performed using a multipoint spectrophotometer at $570 \mathrm{~nm}$ wavelength (Campbell et al., 2010). Cresol indicator changes its color from pink to yellow with decreasing $\mathrm{pH}$ of the gel. The advantage of this method is that the indicator is not in direct contact with the sample (Drage et al., 2012).

The soil samples were prepared by sieving through a $2.0 \mathrm{~mm}$ stainless steel sieve, removing also organic components and stones and were stored at $-18^{\circ} \mathrm{C}$. Before analyzing, the soil samples were pre-incubated at $20^{\circ} \mathrm{C}$ for $2-3$ days to permit the microbial community to recover. The typical amount of soil required for a 96-well plate is 35-50 $\mathrm{g}$ fresh soil. To measure the soil moisture content, 5-10 g of soil were used and the soil was adjusted at $15 \%$ water content.

\section{Statistical analysis}

The data was statistically analyzed using Statistica Starsoft and Past software. To evaluate the effects of soil, moisture and type of fertilizers on microbial community changes, a multivariate analysis of variance (MANOVA) was conducted using Statistica. Principal Component Analysis (PCA) was performed using Past statistical software in order to identify the principal direction on which the MicroResp data vary in function of which type of fertilizers were used, type of soil and water regime. 


\section{RESULTS AND DISCUSSIONS}

Overall, soil microbial activity measured as average of respiration has the lowest values given by arginine, irrespective of the type of soil and water regime used, having lower values than the basal respiration (water), and the highest values of the respiration being given by the $\alpha$-ketoglutaric acid, followed by malic acid, oxalic acid and citric acid.

Furthermore, observing the differences between fertilizer types in response to microbial activity, has been noticed that the highest average activity of all carbon sources was generally given by green manure (Fig. 4).

Making a difference between the metabolic activity of microbial communities from luvisol and chernozem treatments, it was observed that the mean respiration rate was higher in the luvisol treatments with the mean value of $1.749 \mu \mathrm{g} / \mathrm{g} / \mathrm{h}$ $\mathrm{CO}_{2}-\mathrm{C}$. The use of carbon sources was similar, the difference was given by malic and oxalic acids with significantly lower values in the treatments where chernozem was used (Fig. 2).

Considering the applied hydric regime it was observed that for the treatments where an optimal water regime was applied the respiration values were higher for citric, $\alpha$-ketoglutaric, malic and oxalic acids and it was lower for the rest of the carbon sources compared with the treatments where water stress regime was applied. The average of all carbon sources was almost equal for the two water regimes with the value of $1,715 \mu \mathrm{g} /$ $\mathrm{g} / \mathrm{h} \mathrm{CO}_{2}-\mathrm{C}$ for the optimal water regime treatments and $1,708 \mu \mathrm{g} / \mathrm{g} / \mathrm{h} \mathrm{CO}_{2}-\mathrm{C}$ for the treatments where water stress was applied (Fig. 3).

Following the results of multivariate analysis of variance it was observed that the microbial activity significant differences were given by the type of fertilizer, the soil type together with hydric regime used and by the hydric regime together with the fertilizer (Tab. 2). A cluster analysis was also used to find similarities in the microbial community and to observe how the profile of microbial community changes depending on the type of soil, water regime and fertilizer used. For the graphic representation, principal component one and two were used, being the most important, explaining together $77 \%$ of variance (Fig. 5).

The PCA analysis presents a clear separation between the microbial communities in the soil, a grouping made especially depending on the type of water regime applied, and the main carbon sources in the MicroResp analysis that influenced this type of clustering were $\alpha$-ketoglutaric acid and oxalic acid.

Furthermore, for treatments where chernozem was used, the application of any type of fertilizer will change the profile of the microbial community in an opposite direction from the initial community, as well as their grouping being more concentrated. In case of the luvisol, a specific pattern of shifts in the microbial community was observed. The microbial profile which is present in the treatments where mineral fertilizer was used is on opposite direction with the ones from treatments where green manure and cattle manure were used and the community which is formed in slurry manure treatments is always between these two communities (Fig. 5).

It can be noticed that after the addition of carbon sources through different fertilizers, positive priming effect was observed for some treatments and negative for others. However, making an average of all carbon sources used in the MicroResp method for each treatment, it was observed that mineral fertilization has lower metabolism than control treatments, irrespective of the type of soil and the applied water regime. Therefore the priming effect induced by mineral fertilization was negative with respiration values ranging from 0.841 to $1.578 \mu \mathrm{g} / \mathrm{g} / \mathrm{h} \mathrm{CO} \mathrm{CO}_{2}-\mathrm{C}$. For the optimal water regime treatments, the priming effect was positive for organic fertilizers, with the highest values given by green manure followed by cattle manure and slurry manure. For the treatments where water stress was applied it was observed that the priming effect was negative for all fertilization type, except for the green fertilizer in chernozem treatments (Fig. 1). As in our case, Fontaine et al. (2007) suggested that adding green fertilizer leads to a positive priming effect by increasing mineralization by the microbial community of organic matter in the soil.

In any case, both the initial soil community and the communities formed in the other treatments prefer carboxylic acids with a maximum value of $3.671 \mu \mathrm{g} / \mathrm{g} / \mathrm{h} \mathrm{CO}_{2}-\mathrm{C}$, followed by carbohydrates with $1.359 \mu \mathrm{g} / \mathrm{g} / \mathrm{h} \mathrm{CO}_{2}-\mathrm{C}$, amino sugars with 1.117 $\mu \mathrm{g} / \mathrm{g} / \mathrm{h} \mathrm{CO}_{2}-\mathrm{C}$ and amino acids with $0.882 \mu \mathrm{g} / \mathrm{g} / \mathrm{h}$ $\mathrm{CO}_{2}-\mathrm{C}$, pattern repeated irrespective of the type of soil used, the applied water regime and the type of fertilizer used, the separation between 


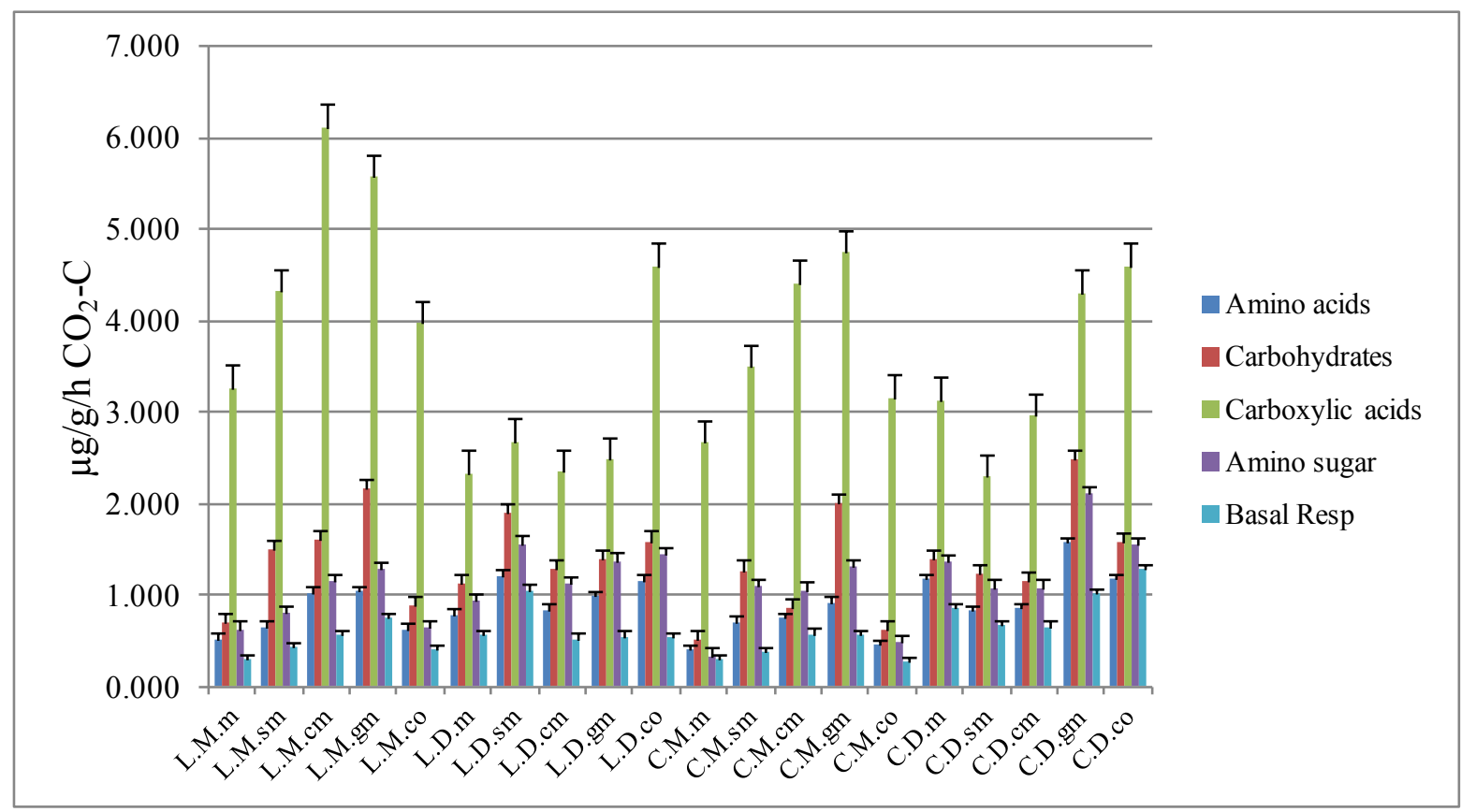

Fig. 1. Mean catabolic response of the microbial community for carbon sources groups (L. - luvisol; C. - chernozem; M.- normal water regime (moist); D. - drought regime (drought), $\mathrm{m}$ mineral fertilizer, sm - slurry manure fertilizer, $\mathrm{cm}$ - cattle manure fertilizer, gm - green manure fertilizer, co - control with no fertilizer;)

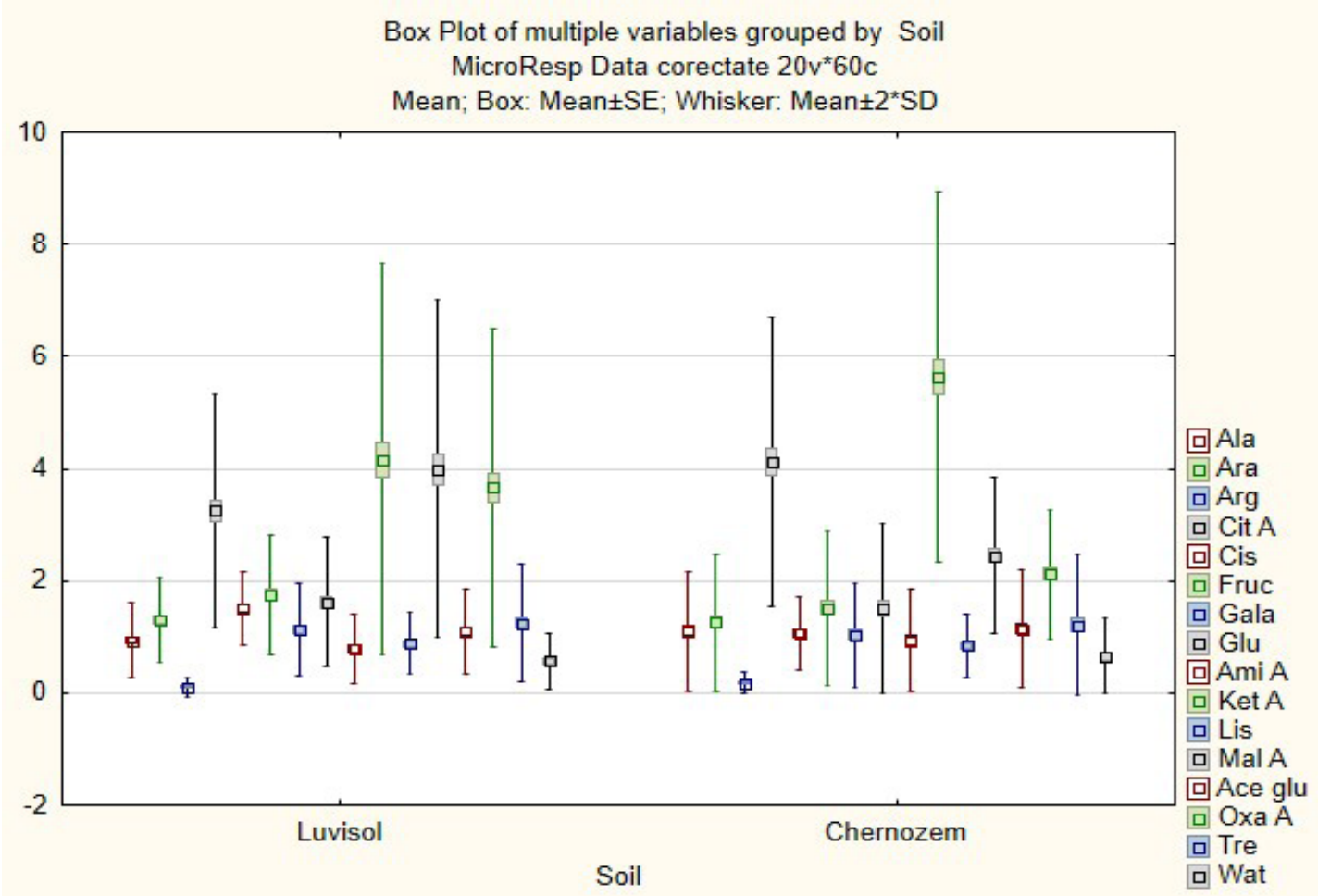

Fig. 2. Mean catabolic response of the microbial community depending on the type of soil 


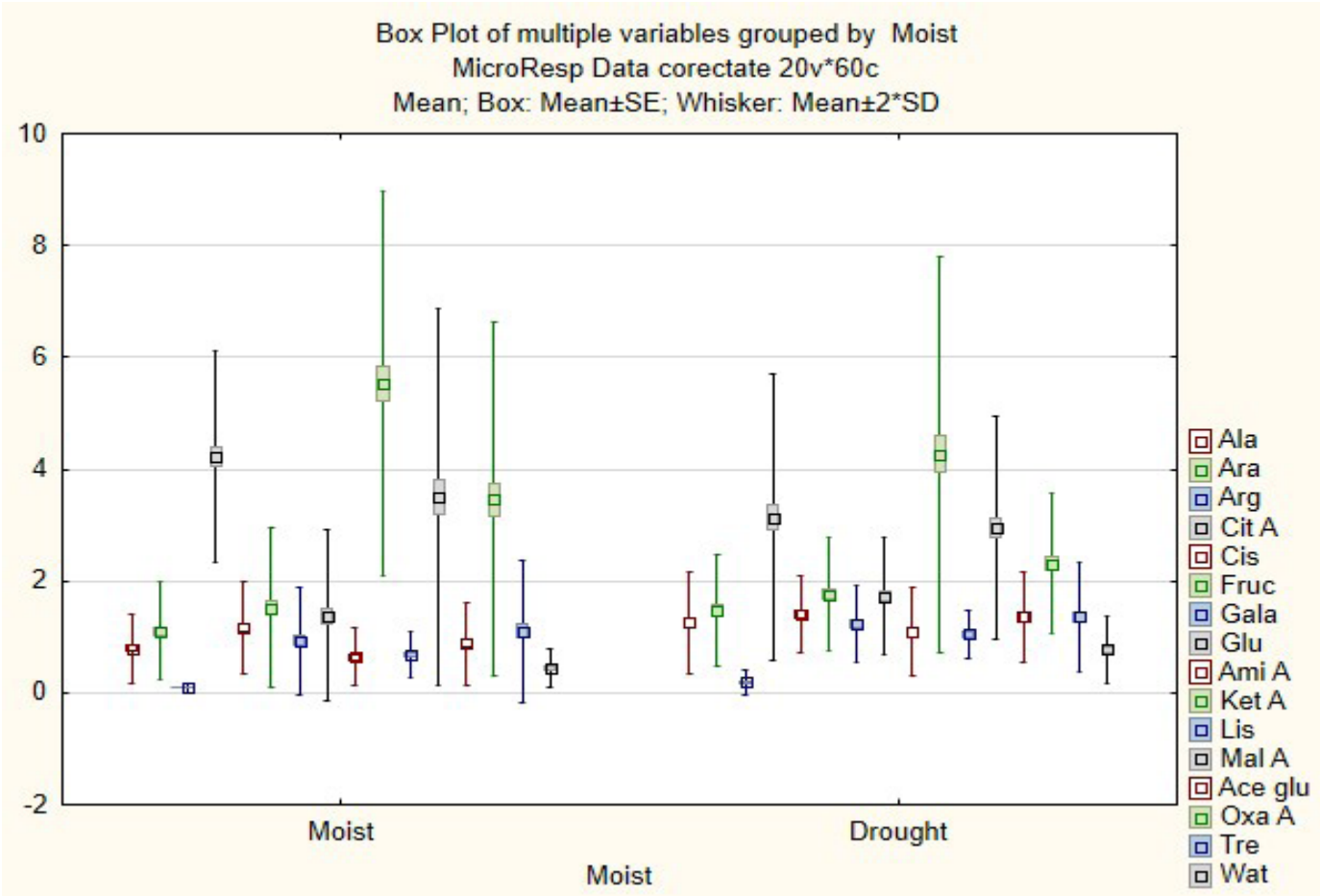

Fig. 3. Mean catabolic response of the microbial community depending on the type of water regime

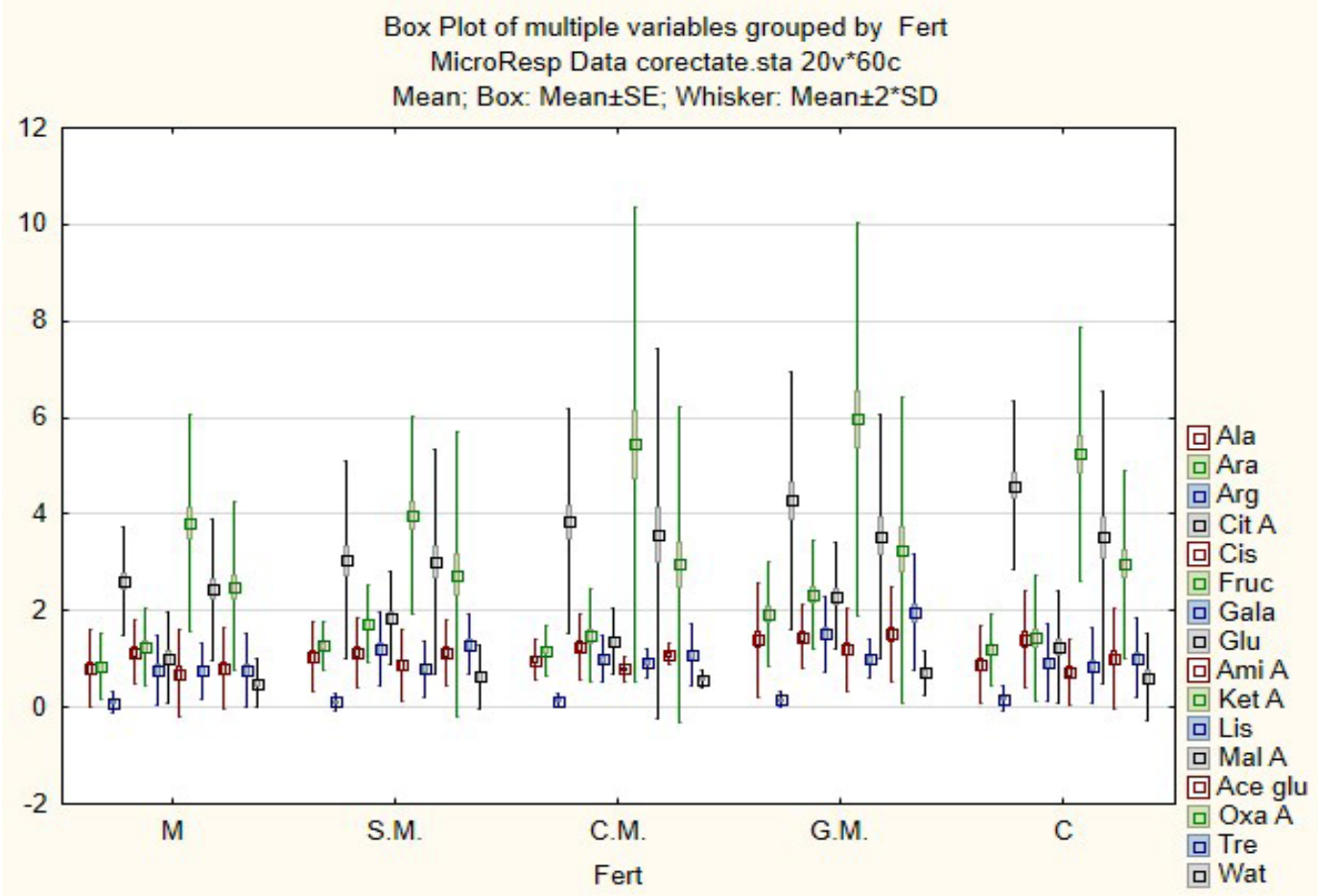

Fig. 4. Mean catabolic response of the microbial community depending on the type of fertilizer

( $\mathrm{M}$ - mineral fertilizer, S.M. - slurry manure fertilizer, C.M. - cattle manure fertilizer, G.M. - green manure fertilizer, C - control with no fertilizer;) 


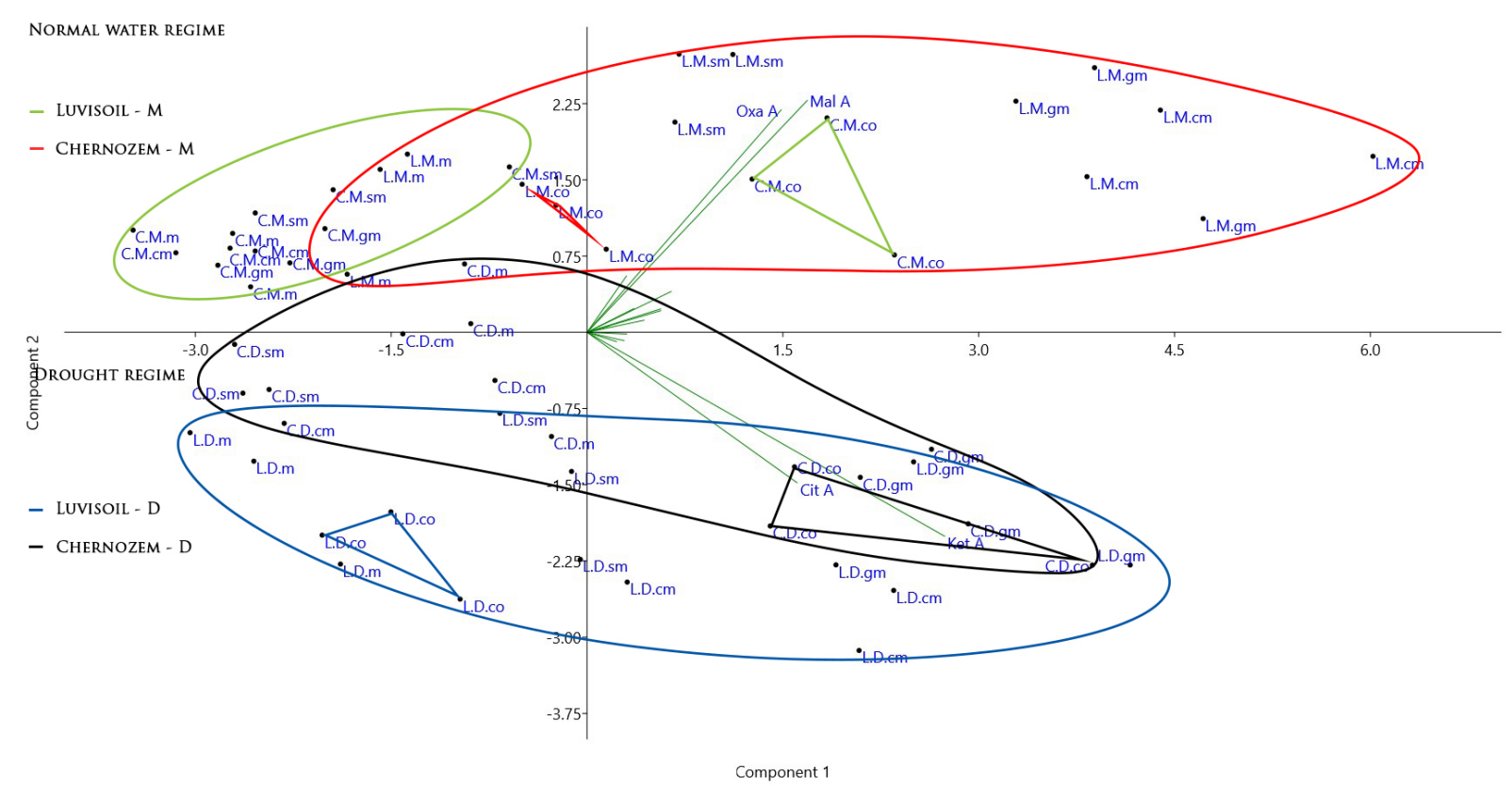

Fig. 5. MicroResp data principal component analysis

(L. - luvisol; C. - chernozem; M.- normal water regime (moist); D. -drought regime (drought), m - mineral fertilizer, sm - slurry manure fertilizer, $\mathrm{cm}$ - cattle manure fertilizer, gm - green manure fertilizer, co - control with no fertilizer;)

Tab. 2. Multivariate analysis of variance (MANOVA)

\begin{tabular}{lccl}
\hline & Effect & $\mathrm{F}$ & $\mathrm{p}$ \\
\hline Intercept & 2812.694 & 0.000 & $* * *$ \\
\hline Soil & 1.347 & 0.418 & n.s. \\
\hline Moist & 0.012 & 0.939 & n.s. \\
\hline Fert & 73.353 & 0.000 & $* * *$ \\
\hline Soil*Moist & 23.648 & 0.000 & $* * *$ \\
\hline Soil*Fert & 17.950 & 0.069 & n.s. \\
\hline Moist*Fert & 65.388 & 0.000 & $* * *$ \\
\hline Soil*Moist*Fert & 16.252 & 0.096 & n.s. \\
\hline Error & & & \\
\hline
\end{tabular}

${ }^{*} \mathrm{p}<0.05,{ }^{* *} \mathrm{p}<0.01,{ }^{* * *} \mathrm{p}<0.001$, n.s. - not significant

communities being made by the type and amount of carbon source used from the large group (Fig. 1).

The results indicate that organic fertilization increases the metabolic activity of the microbial community in the soil under conditions of optimum soil moisture compared to mineral fertilization. Sradnick et al. (2013) observed in an experiment that assessed the functional diversity of the microbial community in long-term fertilized soils with cattle manure and mineral fertilizer, that the functional diversity increases for the treatments where organic fertilizer has been added. In both fertilization treatments the microbial community preferred carbon sources from the group of the carboxylic acid followed by carbohydrates and amino acids, results which are similar with the ones 
from our study. One of the reasons that can lead to these results is that organic fertilization increases microbial biomass compared to the mineral one (Heitkamp et al., 2009; Heinze et al., 2010). Also, some results suggest that microorganisms with high activity such as r-strategy bacteria influence the catabolic response (Degens et al., 2000; Wakelin et al., 2008).

It was also noted that the catabolic response of the microbial community for the treatments where organic fertilizers were used differs, the highest values being given by green fertilizer, followed by cattle manure and slurry manure, difference which may be due to the amount of $\mathrm{C}$ and $\mathrm{N}$ introduced through fertilization and the degree of availability.

Our recommendation is to carry out this type of studies on priming effect using the MicroResp method to succeed in improving it for this purpose. However, through this study, it has been shown that the MicroResp method can be used to identify the priming effect and quantify the carbon mineralisation rate as well as to achieve a profile of the microbial community. If MicroResp will be perfected for the purpose of studying the priming effect, with only one method the carbon turnover can be assessed and also profiling of the microbial community can be made.

\section{CONCLUSIONS}

Functional diversity changes in the microbial community of the soil, according to our results, begin to be individualized within the first ten days depending on the type of soil used, water regime and the type of fertilizer input. Even if the profile of the microbial community changes depending on the factors listed above, it does not manage to get a radical change from the native soil community. In any case, both the initial soil community and the communities formed in the other treatments prefer carboxylic acid carbon sources followed by carbohydrates, amino sugars and amino acids, the separation between communities being made by the type and amount of carbon source used from the large group.

Furthermore, it was noticed that the integration in soil of different carbon sources such as green manure can lead to a positive priming effect and the use of mineral fertilizers can lead to negative priming effect.
Following the undertaken research, it can be stated that the integration of carbon sources into the soil lead to changes within the microbial soil community in the first ten days, and that the MicroResp technique is a method that can be used to identify the priming effect and for quantification of carbon turnover.

ACKNOWLEDGEMENT: This work was supported by a grant of the Romanian National Authority for Scientific Research and Innovation, CNCS - UEFISCDI, project number PN-II-RUTE-2014-4-2490

\section{REFERENCES}

1. Banning NC, Lalor BM, Cookson WR, Grigg AH, Murphy DV (2012). Analysis of soil microbial community level physiological profiles in native and post-mining rehabilitation forest: Which substrates discriminate? Applied Soil Ecology 56:27-34.

2. Bird JA, Herman DJ, Firestone MK (2011). Rhizosphere priming of soil organic matter by bacterial groups in a grassland soil. Soil Biology \& Biochemistry 43:718-725.

3. Blagodatskaya EV, Blagodatsky SA, Anderson TH, Kuzyakov Y (2007). Priming effects in Chernozem induced by glucose and $\mathrm{N}$ in relation to microbial growth strategies. Applied Soil Ecology 37:95 - 105.

4. Blagodatskaya E, Kuzyakov Y (2008). Mechanisms of real and apparent priming effects and their dependence on soil microbial biomass and community structure: critical review. Biol Fertil Soils, 45:115-131.

5. Campbell CD, Chapman SJ, Cameron CM, Davidson MS, Potts JM (2003). A Rapid Microtiter Plate Method To Measure Carbon Dioxide Evolved from Carbon Substrate Amendments so as To Determine the Physiological Profiles of Soil Microbial Communities by Using Whole Soil. Applied and Environmental Microbiology, 35933599.

6. Campbell C, Chapman S, Davidson M (2010). MicroResp Technical Manual, Macaulay Scientific Consulting Ltd, Scotland UK.

7. Chapman SJ, Campbell CD, Rebekka RE (2007). Assessing CLPPs using MicroResp ${ }^{\mathrm{TM}}$, a comparison with Biolog and multi-SIR. J Soils Sediments, 7(6):406-410.

8. Degens BP, Schipper LA, Sparling GP, Vukovic VM (2000). Decreases in organic $C$ reserves in soils can reduce the catabolic diversity of soil microbial communities. Soil Biol. Biochem., 32:189-196.

9. Drage S, Engelmeier D, Bachmann G, Sessitsch A, Mitter B, Hadacek F (2012). Combining microdilution with MicroResp ${ }^{\mathrm{TM}}$ : Microbial substrate utilization, antimicrobial susceptibility and respiration. Journal of Microbiological Methods, 88:399-412.

10. Fontaine S, Mariotti A, Abbadie L (2007), The priming effect of organic matter: a question of microbial competition?, Soil Biology \& Biochemistry, 35:837-843. 
11. Frąc M, Oszust K, Lipiec J (2012). Community Level Physiological Profiles (CLPP), Characterization and Microbial Activity of Soil Amended with Dairy Sewage Sludge. Sensors, 12:3253-3268; doi:10.3390 s120303253.

12. Ge T, Chen X, Yuan H, Li B, Zhu H, Peng P, Li K, Jones DL, Wu J (2013). Microbial biomass, activity, and community structure in horticultural soils under conventional and organic management strategies. European Journal of Soil Biology, 1-7.

13. Heinze S, Raupp J, Joergensen RG (2010). Effects of fertilizer and spatial heterogeneity in soil $\mathrm{pH}$ on microbial biomass indices in a long-term field trial of organic agriculture. Plant Soil 328, 203-215.

14. Heitkamp F, Raupp J, Ludwig B (2009). Impact of fertilizer type and rate on carbon and nitrogen pools in a sandy Cambisol. Plant Soil, 319:259-275.

15. Kuzyakov Y, Friedel JK, Stahr K (2000). Review of mechanisms and quantification of priming effects. Soil Biology \& Biochemistry, 32:1485-1498.

16. Lagomarsino A, Knapp BA, Moscatelli MC, Angelis P, Grego S, Insam H (2007). Structural and Functional Diversity of
Soil Microbes is Affected by Elevated [CO2] and N Addition in a Poplar Plantation. J Soils Sediments, 7(6):399-405.

17. Pignataro A, Moscatelli MC, Mocali S, Grego S, Benedetti A (2012). Assessment of soil microbial functional diversity in a coppiced forest system. Applied Soil Ecology 62:115123 .

18. Sassi MB, Dollingera J, Renaulta P, Tlili A, Bérard A (2012). The FungiResp method: An application of the MicroRespTM method to assess fungi in microbial communities as soil biological indicators. Ecological Indicators, 23:482-490.

19. Sradnick A, Murugan R, Oltmanns M, Raupp J, Joergensen RG (2013). Changes in functional diversity of the soil microbial community in a heterogeneous sandy soil after long-term fertilization with cattle manure and mineral fertilizer. Applied Soil Ecology,63:23-28.

20. Wakelin SA, Macdonald LM, Rogers SL, Gregg AL, Bolger TP, Baldock JA (2008). Habitat selective factors influencing the structural composition and functional capacity of microbial communities in agricultural soils. Soil Biology \& Biochemistry, 40:803-813. 